\title{
Anatomical Variations of Infraorbital Foramen in Dry Human Adult Egyptian Skulls, Anthropometric Measurements and Surgical Relevance
}

\author{
Ezzeddin Elsheikh, Wail Fayez Nasr, Amal Al Shahat Ibrahim
}

\begin{abstract}
Objectives: Evidence supports a clear racial variation in the position of the infraorbital foramen (IOF). Therefore detailed knowledge of the population specific data on biometric features of (IOF) will facilitate therapeutic, diagnostic and surgical manipulations in the maxillofacial region. The goal of this study was to elucidate the morphological features and precise anatomical position of the (IOF) with reference to surrounding anatomical landmarks in an adult Egyptian population.
\end{abstract}

Materials and methods: Fifty-nine adult dry Egyptian skulls (32 males and 27 females) were assessed to determine the number, shape, orientation, vertical and transverse diameters of the IOF, transverse distance from the IOF to the maxillary midline, the zygomaticomaxillary suture and the vertical distance from the IOF to the infraorbital rim and accessory infraorbital foramen using a metal casting digital vernier caliper. The position of the IOF was determined in relation to the maxillary teeth. The findings indicated that the size of the IOF and the mean distances from the IOF to the maxillary midline, infraorbital rim and foramen was significantly larger in males than in females.

Results: The majority of IOF among the skulls were semilunarshaped in $59.4 \%$ in male skulls and $48.1 \%$ in female skulls. The majority were directed inferomedially in $88.9 \%$ in female skulls and $78.1 \%$ in male skulls. Accessory foramina were found in $21.87 \%$ of male skulls and $18.5 \%$ of female skulls. All had bilateral double foramina except for one male skull and one female skull.

Conclusion: The racial and gender differences of the IOF emphasize the need for meticulous preoperative evaluation of the IOF in patients who are candidates for maxillofacial surgeries and regional block anesthesia.

Keywords: Infraorbital foramen, Infraorbital nerve, Infraorbital vessels.

How to cite this article: Elsheikh E, Nasr WF, Ibrahim AAS. Anatomical Variations of infraorbital Foramen in Dry Human Adult Egyptian Skulls; Anthropometric Measurements and Surgical Relevance. Int J Otorhinolaryngol Clin 2013;5(3):125-129.

Source of support: Nil

Conflict of interest: None declared

\section{INTRODUCTION}

The infraorbital foramen (IOF) is present in the maxilla about $1 \mathrm{~cm}$ below the infraorbital margin. It transmits the infraorbital vessels and nerve. It lies on, or just lateral to, a vertical line passing through supraorbital notch or foramen. ${ }^{1}$

The IOF is relatively larger than the supraorbital foramen and vary in shape and position. ${ }^{2}$
Infraorbital nerve is a continuation of maxillary nerve. It emerges through infraorbital foramen and lies between levator labii superiors and the deeper placed levator anguliaris. It is a large sensory nerve that immediately breaks up into several branches; these radiate away from the foramen to supply the lower eye lid, check, nose, upper lip and labial gum. ${ }^{3}$

IOF is an important anatomical landmark to facilitate surgical, local anesthetic and other invasive procedures for oral and maxillofacial surgeries. So, efficient knowledge of regional anatomy is important to avoid injury to the neurovascular bundles passing through the foramen. ${ }^{4}$

The position of IOF varies among racial group. ${ }^{5,6}$ Furthermore, the position of IOF in relation to the maxillary teeth is shown to be varied among population. ${ }^{7,8}$ For this cause, this work was designed to investigate the shape, orientation and dimensions of infraorbital foramen in relation to the surgically encountered anatomical landmarks in an adult Egyptian population.

\section{MATERIALS AND METHODS}

A total of 59 adult dry skulls (32 male and 27 female) collected from the Department of Anatomy and Embryology, Faculty of Medicine, Zagazig University, Egypt were used for this study. The determination of sex was based on the following facts, the female skull is little lighter and smaller than male skull. Its walls are thinner and its muscular ridges less marked; the glabella, supraciliary arches and mastoid processes are less prominent. The upper margin of orbit is sharp, forehead vertical, the frontal and parietal tubrosities are prominent and the vault somewhat flattened. ${ }^{1,9}$

Both foramina were inspected for determination of shape, direction and location in relation to maxillary teeth. The greatest transverse and vertical diameters of infraorbital foramina were recorded. Also, the distance between the center of the IOF and zygomaticomaxillary suture and the vertical distance from IOF to the infraorbital rim were recorded. All measurements were recorded using a metal casting digital vernier caliper (Guilin Guanglu Measuring Instruments, Guilin, China) with accuracy of up to $0.01 \mathrm{~mm}$.

All measurements were repeated twice made by the same person and the mean was taken for further analysis. Results were expressed as mean \pm SD and analyzed using the 
statistical package for social science (SPSS), version. A comparison of the mean values between genders was performed by using the t-test. p-value $<0.05$ was considered statistically significant (Figs 1 to 3 ).

\section{RESULTS}

All skulls examined revealed the presence of infraorbital foramen on both sides.

The shape of infraorbital foramen was semilunar in $59.4 \%$ in male skulls and $48.1 \%$ in female skulls, oval in $12.5 \%$ in male skulls and $7.4 \%$ in female skulls, rounded in $28.1 \%$ in male skulls and $44.4 \%$ in female skulls with no significant difference between the genders (Table 1 and Graph 1).

The direction of infraorbital foramen was infromedially in $78.1 \%$ in male skulls and $88.9 \%$ in female skulls and medially directed in $21.9 \%$ in male skulls and $11.1 \%$ in female skulls with no significant difference between the genders (Tables 2 and 3).

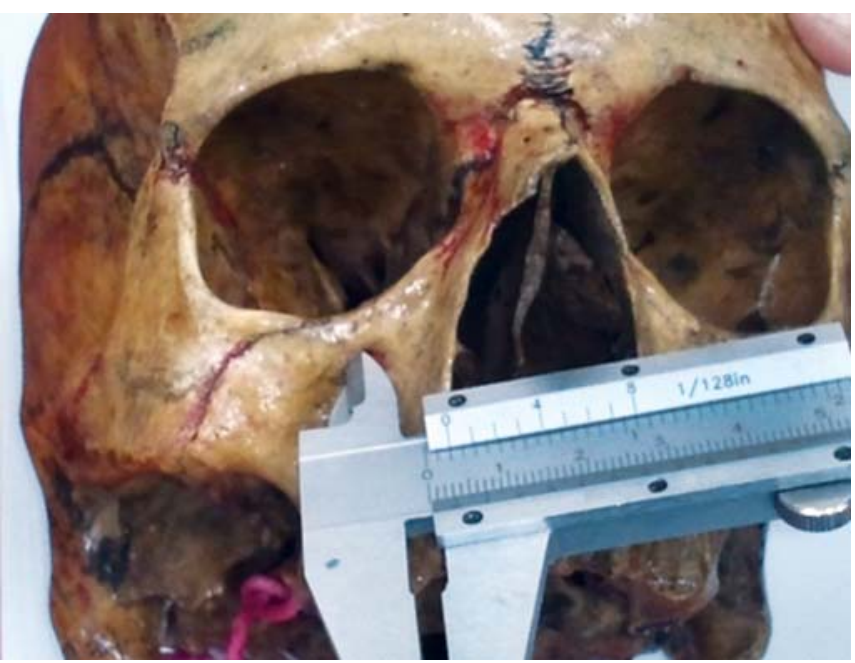

Fig. 1: Measurement of the transverse diameter of the IOF

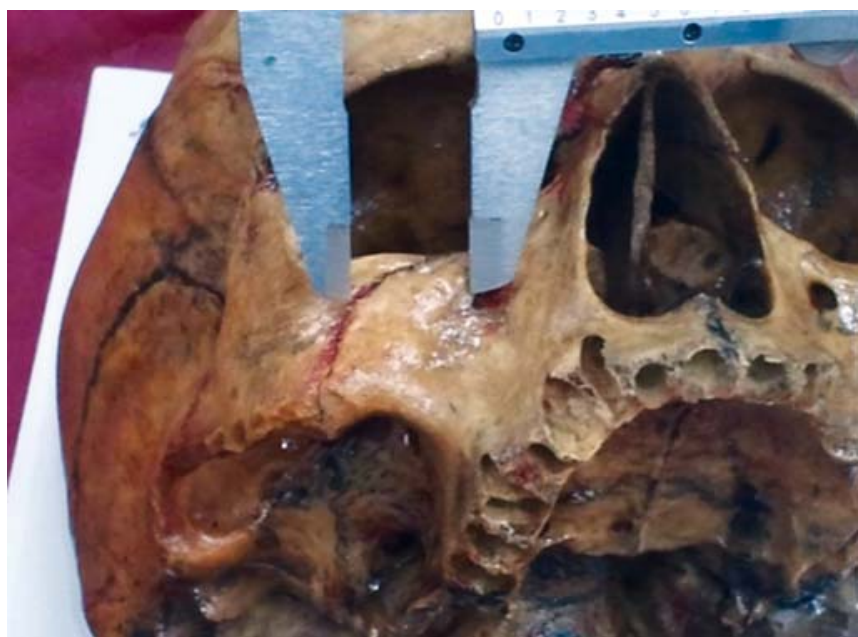

Fig. 3: Measurement of the distance between the center of the IOF and zygomaticomaxillary suture
The comparison between male and female in morphometric data of left and right infraorbital foramen were showed in Table 4 with no significant difference for all parameters except for the distance between left and right infraorbital foramen and zygomaticomaxillary suture. Also, there was significant difference in the maximum transverse diameter of left infraorbital foramen.

Accessory foramina were found in $21.87 \%$ of male skulls and $18.5 \%$ of female skulls. The skulls that showed multiple foramina, all had bilateral double foramina (one main IOF foramen and one accessory IOF) except for one male skull and one female skull in which one side with double foramen and the other side with only main IOF (Figs 4 and 5).

Frequencies of position of IOF in relation to the upper teeth are shown in Table 5 and Graph 2. The most common position for infra orbital foramen relative to the upper teeth was found to be in line with the second upper premolar (46.87\%) in male skulls and (66.6\%) in female skulls followed by opposition in line with 1st premolar (28.125\%)

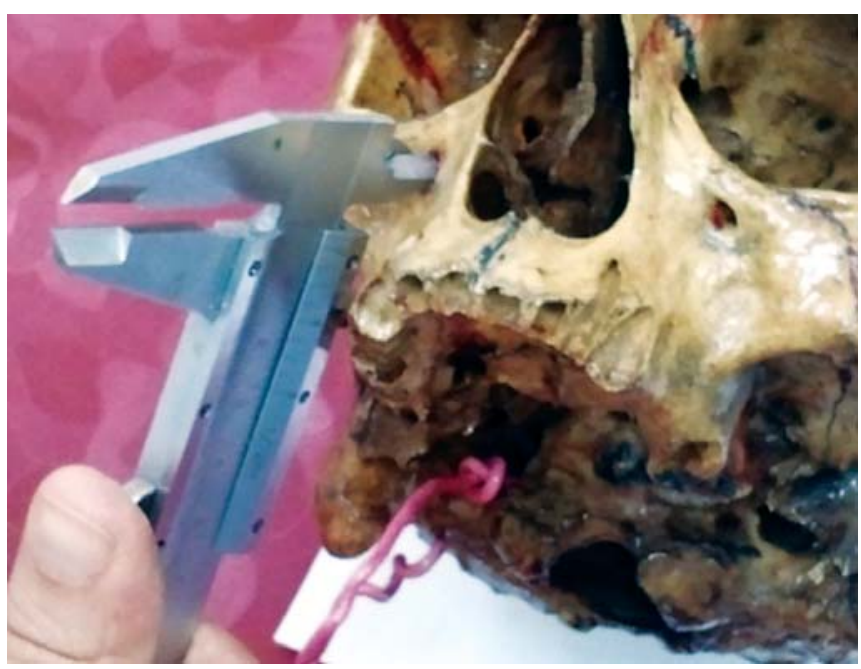

Fig. 2: Measurement of the vertical diameter of the IOF

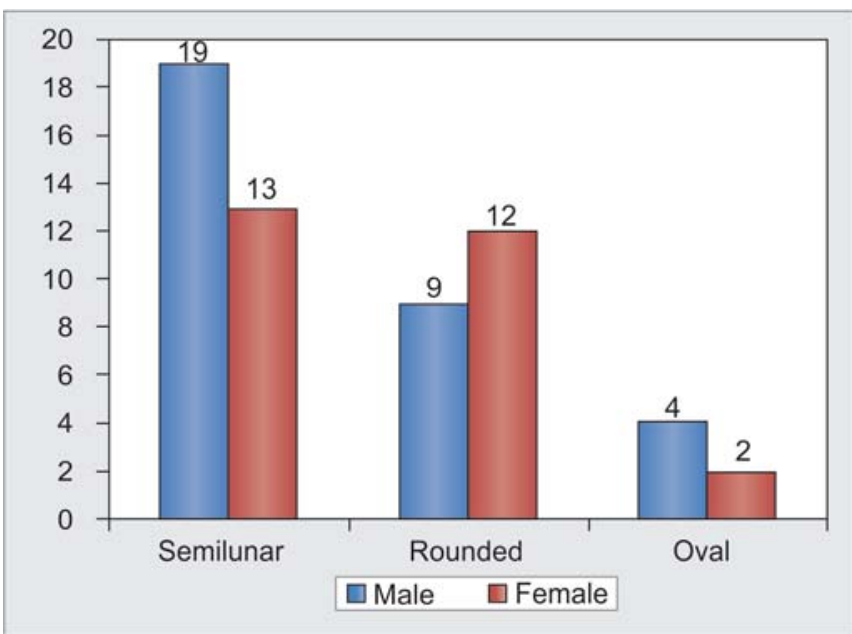

Graph 1: The frequency of shape of IOF between genders 
Table 1: Frequency of the shape of infraorbital foramen between genders

\begin{tabular}{|c|c|c|c|c|c|}
\hline \multirow[t]{2}{*}{ Shape } & \multicolumn{2}{|c|}{ Male } & \multicolumn{2}{|c|}{ Female } & \multirow[t]{2}{*}{$p$-value } \\
\hline & $N$ & $x$ & $N$ & $x$ & \\
\hline Semilunar & 19 & 59.4 & 13 & 48.1 & \\
\hline Rounded & 9 & 28.1 & 12 & 44.4 & 0.4 \\
\hline Oval & 4 & 12.5 & 12 & 7.4 & \\
\hline
\end{tabular}

N: Number; $X:$ Percentage; $p \leq 0.05$
Table 2: Direction of infraorbital foramen between genders

\begin{tabular}{lllllll}
\hline Direction & \multicolumn{2}{c}{ Male } & & \multicolumn{2}{c}{ Female } & p-value \\
\cline { 2 - 3 } & $N$ & $X$ & & $N$ & $X$ & \\
\hline Inferomedially & 25 & 78.1 & & 24 & 88.9 & 0.31 \\
Medially & 7 & 21.9 & & 3 & 11.1 & \\
\hline
\end{tabular}

Table 3: Descriptive data of infraorbital foramina among the genders

\begin{tabular}{|c|c|c|}
\hline & $\begin{array}{l}\text { Rt infraorbital foramen } \\
\text { (mean } \pm S D) \mathrm{mm}\end{array}$ & $\begin{array}{l}\text { Lt infraorbital foramen } \\
(\text { mean } \pm S D) \mathrm{mm}\end{array}$ \\
\hline Maximum transverse diameter & $3.2 \pm 0.98$ & $3.37 \pm 0.99$ \\
\hline Maximum vertical diameter & $3.38 \pm 0.76$ & $3.4 \pm 0.75$ \\
\hline Distance from IOF to ZMS & $13.0 \pm 2.5$ & $13.0 \pm 2.8$ \\
\hline Distance from IOF to IOR & $6.2 \pm 1.4$ & $6.5 \pm 1.3$ \\
\hline
\end{tabular}

IOF: Infraorbital foramen; IOR: Infraorbital ridge; ZMS: Zygomaticomaxillary suture

Table 4: The comparison between male and female in morphometric data of left and right infraorbital foramen

\begin{tabular}{lccl}
\hline & $\begin{array}{c}\text { Male }(n=32) \\
(\text { mean } \pm \text { SD }) ~ m m\end{array}$ & $\begin{array}{c}\text { Female }(n=27) \\
(\text { mean } \pm S D) ~ m m\end{array}$ & p-value \\
\hline Rt infraorbital foramen & & & \\
Maximum transverse diameter & $3.3 \pm 1.0$ & $3.0 \pm 0.86$ & 0.23 \\
Maximum vertical diameter & $3.4 \pm 0.7$ & $3.3 \pm 0.8$ & 0.63 \\
Distance from IOF to ZMS & $13.9 \pm 2.4$ & $11.9 \pm 1.9$ & $0.0014^{*}$ \\
Distance from IOF to IOR & $6.37 \pm 1.4$ & $6.1 \pm 1.36$ & 0.45 \\
Lt infraorbital foramen & & & \\
Maximum transverse diameter & $3.7 \pm 0.97$ & $3.0 \pm 0.9$ & $0.008^{*}$ \\
Maximum vertical diameter & $3.5 \pm 0.79$ & $3.3 \pm 0.7$ & 0.22 \\
Distance from IOF to ZMS & $13.99 \pm 2.8$ & $11.8 \pm 2.3$ & $0.002^{*}$ \\
Distance from IOF to IOR & $6.7 \pm 1.6$ & $6.2 \pm 0.9$ & 0.09 \\
\hline
\end{tabular}

*Significant difference between genders at $p<0.05$

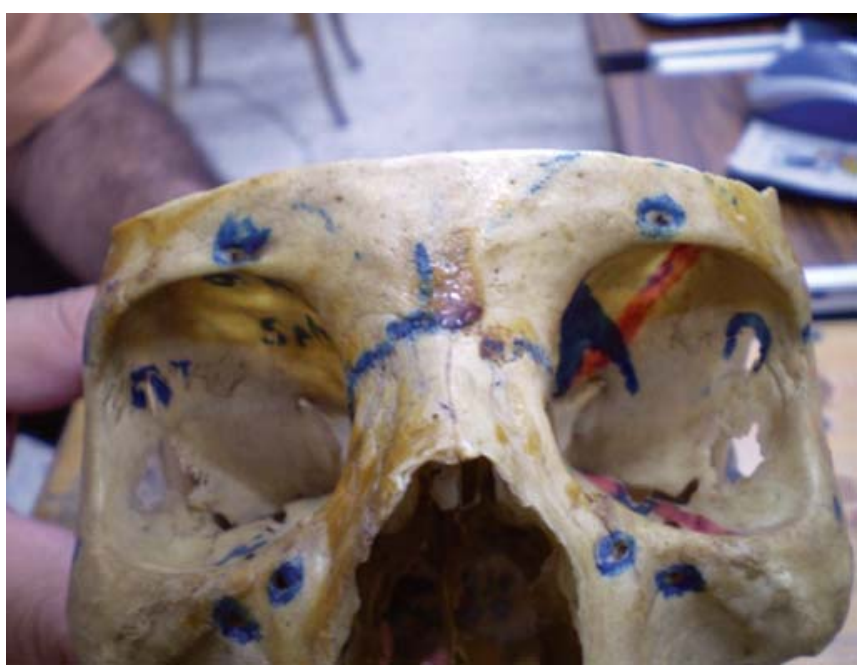

Fig. 4: Skull showing double accessory IOF, both main IOF are rounded and directed medially, both accessory IOF are supramedially directed
Table 5: Frequency of position of IOF in relation to upper teeth

\begin{tabular}{|c|c|c|c|c|}
\hline & \multicolumn{2}{|c|}{ Male } & \multicolumn{2}{|c|}{ Female } \\
\hline & $N$ & $x$ & $N$ & $x$ \\
\hline 2nd premolar & 15 & 46.87 & 18 & 66.6 \\
\hline 1st premolar & 9 & 28.125 & 8 & 29.62 \\
\hline $\begin{array}{l}\text { Line between } \\
\text { 1st and 2nd } \\
\text { premolar }\end{array}$ & 5 & 15.62 & 1 & 3.07 \\
\hline 1st molar & 3 & 9.37 & 0 & - \\
\hline
\end{tabular}

in male skulls and (29.62\%) in female skulls. The infraorbital foramen was in line between 1st and 2nd upper premolar in (15.62\%) in male skulls and (3.70\%) in female skulls.

However, the position of infraorbital foramen in line with 1st upper molar tooth is (9.37\%) in male skulls only. 


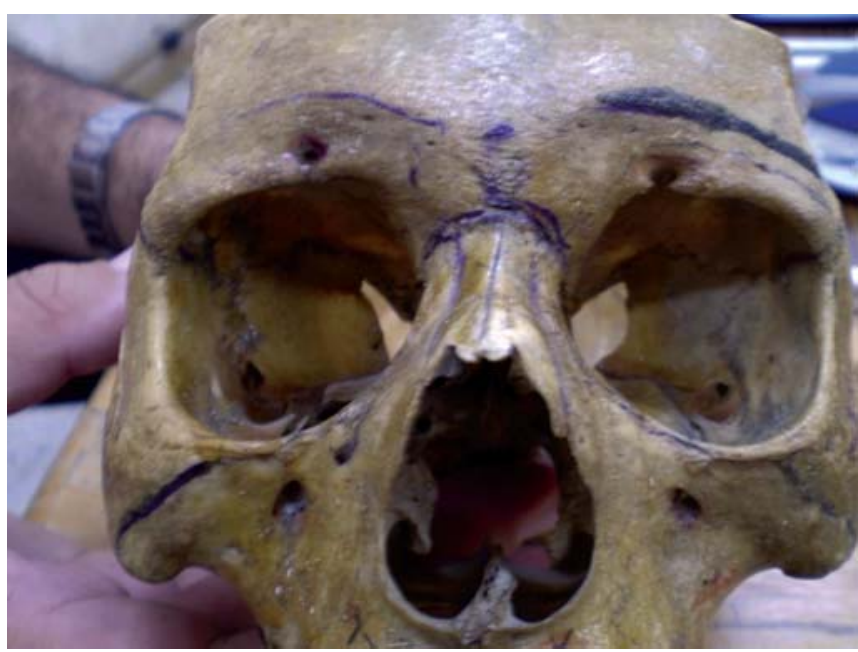

Fig. 5: Skull showing the inferomedially placed accessory IOF in the right side only and the both main IOF is ovoid and its opening directed downward and medially in both sides

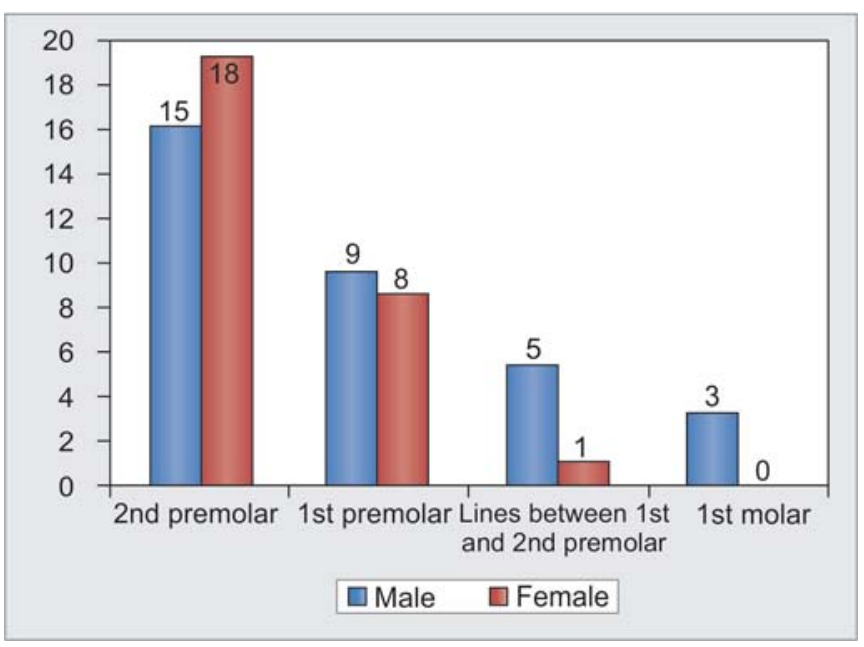

Graph 2: Frequency of position of infraorbital foramen in relation to upper teeth

\section{DISCUSSION}

The accurate identification of IOF is important for both diagnostic and clinical procedures. Clinically, nerve bundles emerging from this foramen could be injured during surgical procedures, resulting in paresthesia or anesthesia. So, understanding of anatomical position of IOF is of increased importance with rising popularity of endoscopic procedures with limited visibility. ${ }^{10}$

The present study showed presence of infraorbital foramina bilaterally in all examined skulls this is in agreement with previous studies. ${ }^{4,6,11}$ The current work showed the incidence of accessory foramina (21.87\%) for male skulls and (8.51\%) for female skulls with $20.33 \%$ for total number of skulls. This is consistent with the corresponding figures reported by some studies. ${ }^{12,13}$ But, it was larger than the frequencies reported by others ${ }^{4,6,14}$ the knowledge of presence of accessory foramina is advantageous to avoid anesthetic complication as partial nerve block or causing injury to any of the branches of infraorbital nerve that may result in sensory deficit. ${ }^{13}$ The presence of accessory foramina is due to branching of nerves during development. ${ }^{5}$ The shape of infraorbital foramen in this study showed the higher incidence for semilunar, but this disagreed with the previous studies ${ }^{4,8,15,16}$ as semilunar shaped infraorbital foramen was found to be less compared to that found in above previous studies.

However, the incidence of rounded shaped IOF in this study is higher than the incidence of oval shaped IOF in both genders. This is in accordance with Kazkayasi et al and Elias et al but other studies ${ }^{4,16}$ Showed the reverse. The most common direction of infraorbital foramen was inferomedially with no significant gender difference. The above finding is in consistence with previous reports. ${ }^{4,12,14,15}$ Also, this study identifies medially directed infraorbital foramen which was in accordance with other reports. ${ }^{16,17}$

The mean distance between infraorbital foramen and infraorbital ridge in this study was $6.7 \mathrm{~mm}$ in male skull and $6.2 \mathrm{~mm}$ in female skull for left infraorbital foramen and was $6.3 \mathrm{~mm}$ in male skull and $6 \mathrm{~mm}$ in female skull for right infraorbital foramen. These figures are in agreement with previous studies. ${ }^{5,15,16,18}$ Those reported the following data $6.4,6.71,6.57$ and $6.70 \mathrm{~mm}$ respectively. While others recorded larger distance between IOF and infraorbital ridge. $4,7,11,17,19$

The mean distance between IOF and zygomaticomaxillary suture was varied among the gender. On right infraorbital foramen the mean distance was $13.9 \mathrm{~mm}$ in male skull and $11.9 \mathrm{~mm}$ in female skull. On left infraorbital foramen the mean distance was $13.99 \mathrm{~mm}$ in male skull and $11.8 \mathrm{~mm}$ in female skull.

The result of this study was in agreement with reports for white and black population. ${ }^{5,7}$

But this finding disagreed with previous reports ${ }^{4,14}$ as they recorded smaller figures than those obtained by this study, further high lighting the racial differences. ${ }^{8}$ The mean distance of right vertical diameter of infraorbital foramen was $3.4 \mathrm{~mm}$ in male skull and $3.3 \mathrm{~mm}$ in female skull. The left vertical diameter was $3.5 \mathrm{~mm}$ in male skulls and $3.3 \mathrm{~mm}$ in female skulls with no significant difference between the genders. This is in accordance with other studies. ${ }^{14,16,20-22}$ But larger distance was recorded by Aziz et al. ${ }^{7}$ The mean distance of right transverse diameter of infraorbital foramen was $3.3 \mathrm{~mm}$ in male skull and $3.0 \mathrm{~mm}$ in female skulls with no significant difference between the genders. The left transverse diameter was $3.7 \mathrm{~mm}$ in male skulls and $3.0 \mathrm{~mm}$ in female skulls with significant difference among genders. Previous studies ${ }^{4,14,16,21,22}$ were recorded figures close to the findings of this study. However, Oliverira et $\mathrm{al}^{20}$ recorded larger transverse diameter $4.2 \mathrm{~mm}$ on right side and $4.33 \mathrm{~mm}$ on left side. 
The most common position of infraorbital foramen with respect to upper teeth was found to be in the same line of upper second premolar followed by a position in line with first premolar then a position in line between first and second upper premolar.

This is in accordance with Aziz et $\mathrm{al}^{7}$ whereas some studies $^{4,13,14}$ disagreed with the finding of this study as they reported that the common position of infraorbital foramen was in line with second upper premolar tooth but the next frequent position was line between first and second premolar.

The results in this study help to determined the more precise location of infraorbital foramen mainly in relation to the infraorbital ridge since this distance has a relevant importance during clinical procedures that use the infraorbital foramen anatomical repair point. ${ }^{23}$ Also, the results of this study confirm the racial difference in the model position of the infraorbital foramen in relation to the upper tooth observed among different population. ${ }^{14}$

\section{CONCLUSION}

The various mean distances constrained by standard deviation as elaborated in table/s determine the exact position of infraorbital foramen in Egyptian population and may be the first hand vital information to concerned clinicians to avoid complications during maxillofacial, Caldwell Luc's surgical procedures and nerve block. The knowledge of the distances from surgically encountered anatomical landmarks in the present study may assist surgeons to localize these important maxillofacial openings avoid injury to the neurovascular bundles and facilitate surgical, local anesthetic and other invasive procedures. The data are of direct relevance to clinical practice and teaching.

\section{REFERENCES}

1. Standring S, Ellis H, Healy JC, Johnson D, Williams A, Collins $\mathrm{P}$, et al. Gray's anatomy. The anatomical basis of clinical practice. 39th ed. Elsevier, Churchill Livingstone, London 2005:511-551.

2. Berge JK, Bergman RA. Variations in size and symmetry of foramina of the human skull. Clin Anat 2001;14:406-413.

3. Mc Minn RMH. Pterygopalatine fossa. In: Sinnatamby CS (ed). Last's Anatomy Regional and Applied. London: Churchill Livingstone 1990:451-467.

4. Apinhasmit W, Chompoopong S, Methathrathip D, Sansuk R, Phetphunphiphat W. Supraorbital notch/foramen, infraorbital foramen and mental foramen in Thais: anthropometric measurements and surgical relevance. J Med Assoc Thai 2006;89:675-682.

5. Cutright B, Quillopa N, Schubert W. An anthropometric analysis of the key foramina for maxillofacial surgery. J Oral Maxillofac Surg 2003;61:354-357.

6. Ongeti K, Hassanali J, Ogeng’o J, Saidi H. Biometrie features of facial foramina in adult Kenyan skulls. Eur J Anat 2008;21: 89-95.

7. Aziz SR, Marchena JM, Puran A. Anatomic characteristics of the infraorbital foramen; a cadaver study. J Oral Maxillofac Surg 2000;58:992-996.
8. Kazkayasi M, Ergin A, Ersoy M, Tekdemir I , Elhan A. Microscopic anatomy of the infraorbital canal, nerve and foramen. Otolaryngol Head Neck Surg 2003;129:692-701.

9. Williams PL, Bannister LH, Berry MM, Collins P, Dyson M, Dussek JE. Gray's anatomy. The anatomical basis of medicine and surgery. 38th Ed. New York, Churchill Livingstone, 2000.

10. Rossi M, Ribeiro E, Smith R. Craniofacial asymmetry in development: an anatomical study. Angle Orthod 2003;73: 381-385.

11. Chung MS, Kim HJ, Kang HS, Chung IH. Locational relationship of the supraobital notch or foramen and infraorbital and mental foramina in Koreans. Acta Anat 1995;154:162-166.

12. Hindy AM, Abdel- Raouf FA. Study of infraorbital foramen, canal and nerve in adult Egyptians. Egypt Dent J 1993;39: 573-580.

13. Poonam JK, Prajna SP, Nirupma G. Morphometric analysis of infraorbital foramen in day adult skulls and its surgical relevance. Journal of Advance Researches in Biological Sciences 2012;4(2):83-87.

14. Ilayperuma I, Nanayakkara G, Palahepitiya N. Morphometric analysis of the infraorbital foramen in adult Sri Lankan skulls. Int J Morphol 2010;28(3):777-782.

15. Elias MG, Silva RB, Pimental ML. Morphometric analysis of the infraorbital foramen and accessories foraminas in Brasillian skulls. Int J Morphol 2004;22:273-278.

16. Boopathi S, Chakravarthy Marx S, Dhalapathy S, Anupa S. Anthropometric analysis of the infra orbital foramen in South Indian population. Singapore Med J 2010;51(9):730.

17. Gour KK, Nair SG, Trivedi N, Gupta SD. Anthropometric measurements of infraorbital foramen in dried human skulls. Int J Biol Med Res 2012;3(3):2003-2006.

18. Karakas P, Bozkir MG, Oguz O. Morphometric measurements from various reference points in the orbit of male Caucasians. Surg Radiol Anat 2002;24(6):358-362.

19. Canan S, Asim OM, Okan B, Ozek C, Alper M. Anatomic variations of the infraorbital foramen. Ann Plast Surg 1999;43:613-617.

20. Junior O, Moreira RT, Neto BL, Silva CM, Lima FJ. A morphological and biometric study of the infraorbital foramen (E2 - Sibai Point) in adult skulls. Int J Morphol 2012;30(3): 986-992.

21. Singh R. Morphometric analysis of infraorbital foramen in Indian dry skulls. Anatomy and Cell Biology 2011;44:79-83.

22. Saheb H, Muralidhar PS, Desai SD, Thomas ST, Maavishettar GF, Asseena HS. Morphometric analysis of infraorbital foramen position in South Indian skulls. Indian J Innovations Dev 2012;1:2277-5390.

23. Macedo VC, Cabrini RR, Faig-Leite H. Infraorbital foramen location in dry human skulls. Braz J Morphol 2009;26(1): 35-38.

\section{ABOUT THE AUTHORS}

\section{Ezzeddin Elsheikh}

Department of Otorhinolaryngology and Head and Neck Surgery Faculty of Medicine, Zagazig University, Egypt

\section{Wail Fayez Nasr (Corresponding Author)}

Department of Otorhinolaryngology and Head and Neck Surgery Faculty of Medicine, Zagazig University, Egypt, Phone: 000552303264 e-mail: wail.fayez@yahoo.com

\section{Amal Al Shahat Ibrahim}

Department of Anatomy, Faculty of Medicine, Zagazig University Egypt 